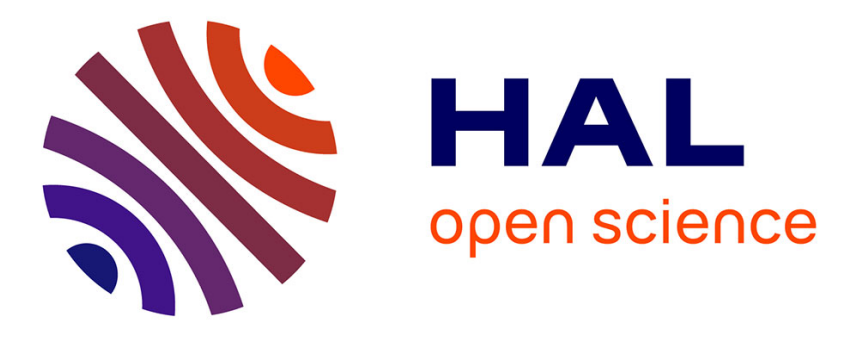

\title{
Electrocaloric Enhancement Induced by Cocrystallization of Vinylidene Difluoride-Based Polymer Blends
}

Florian Le Goupil, Francesco Coin, Naser Pouriamanesh, Guillaume Fleury, Georges Hadziioannou

\section{To cite this version:}

Florian Le Goupil, Francesco Coin, Naser Pouriamanesh, Guillaume Fleury, Georges Hadziioannou. Electrocaloric Enhancement Induced by Cocrystallization of Vinylidene Difluoride-Based Polymer Blends. ACS Macro Letters, 2021, pp.1555-1562. 10.1021/acsmacrolett.1c00576 . hal-03447249

\author{
HAL Id: hal-03447249 \\ https://hal.science/hal-03447249
}

Submitted on 24 Nov 2021

HAL is a multi-disciplinary open access archive for the deposit and dissemination of scientific research documents, whether they are published or not. The documents may come from teaching and research institutions in France or abroad, or from public or private research centers.
L'archive ouverte pluridisciplinaire HAL, est destinée au dépôt et à la diffusion de documents scientifiques de niveau recherche, publiés ou non, émanant des établissements d'enseignement et de recherche français ou étrangers, des laboratoires publics ou privés. 


\section{Electrocaloric Enhancement Induced by Cocrystallization of}

\section{Vinylidene Difluoride-Based Polymer Blends.}

Florian Le Goupil*, Francesco Coin, Naser Pouriamanesh, Guillaume Fleury, and Georges Hadziioannou*

Univ. Bordeaux, CNRS, Bordeaux INP, LCPO, UMR 5629, F-33600, Pessac, France

Email: florian.le-goupil@u-bordeaux.fr, georges.hadziioannou@u-bordeaux.fr

Keywords: electrocaloric effect, ferroelectric polymer, microstructure tuning

Active thermal control will be a major challenge of the twenty-first century, which has emphasized the need for the development of energy-efficient refrigeration techniques such as electrocaloric (EC) cooling. Highly polar semi-crystalline VDF-based polymers are promising organic EC materials, however, their cooling performance, which is highly structurallydependent, needs further improvement to become competitive. Here, we report a simple method to increase the crystalline coherence of $\mathrm{P}(\mathrm{VDF}$-ter-TrFE-ter-CFE) ter-polymer in the plane including the polar direction. This is achieved by blending P(VDF-ter-TrFE-terCFE) with minute amounts of $\mathrm{P}(\mathrm{VDF}-\mathrm{co}$-TrFE) co-polymer with similar VDF/TrFE unit content. This similarity allows for a cocrystallization of the co-polymer chains in the terpolymer crystalline lamellae, preferentially extending the lateral coherence without lamellar thickening, as validated with a wide range of structural characterisation. This results in a significant dielectric and electrocaloric enhancement, with a remarkable electrocaloric effect, $\Delta T_{E C}=5.2 \mathrm{~K}$, confirmed by direct measurements for a moderate electric field of $90 \mathrm{MV} \cdot \mathrm{m}^{-1}$ in a blend with $1 \mathrm{wt} \%$ of $c o$-polymer. 
Projected to be among the main sources of greenhouse gases emissions in the near future, the refrigeration and cooling technology is in dire need for efficient and environmentally-friendly alternatives. Electrocaloric (EC)-based solid-state cooling is a serious candidate, but its potential for applications is still currently stifled by the low performance of EC materials. EC cooling is based on the electrocaloric effect (ECE), which arises from the increase of the net polarization under the application of an external electric field, $E$, in polar crystals. In adiabatic conditions, the system compensates the decrease of dipolar entropy (inherent to the alignment of dipoles) with an increase in lattice vibration entropy, i.e. a temperature increase, therefore keeping the overall entropy of the system constant. ${ }^{1,2}$ In a hysteresis-free environment, this process is fully reversible, and the cooling obtained at the electric field removal is of same amplitude as the heating. This cooling power is governed by the adiabatic temperature change, $\Delta T_{E C}$, of the active material, which corresponds to its temperature change upon application of a given value of electric field. ${ }^{1,3-5} \Delta T_{E C}$ depends on several material specific parameters, the main one of which is the polarization, $P$. A high maximum polarization $P_{\max }$ is thus expected to enhance $\Delta T_{E C}$, and high change in polarization with field, $(d P / d E)$, - i.e. a high relative permittivity, $\varepsilon_{r}$ - ensures the efficiency of the process by achieving this high $\Delta T_{E C}$ at sufficiently low electric fields.

For semi-crystalline polymers such as highly-polar vinylidene difluoride-based (VDF) polymers, which have arisen as the main candidates for polymer-based solid state cooling, ${ }^{4-8}$ both the permittivity and the polarization are highly structurally dependent. The structural parameters of their crystalline lamellae play an especially crucial role (Fig. 1a), including the crystalline lamellar thickness, $L_{c}$, the inter-planar (or inter-chain) distance, $d_{\mathrm{hkl}}$, the crystalline lateral extension, $\xi_{\mathrm{hkl}}$, which includes the polar direction normal to the polymer chains, and the crystallinity (ratio between the volume of the crystalline phases over that of the amorphous phase). These structural parameters are also highly dependent on the polymer chain conformations stable in the crystalline lamellae. 


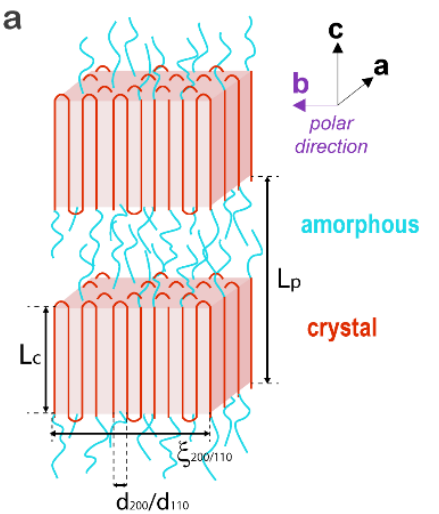

b
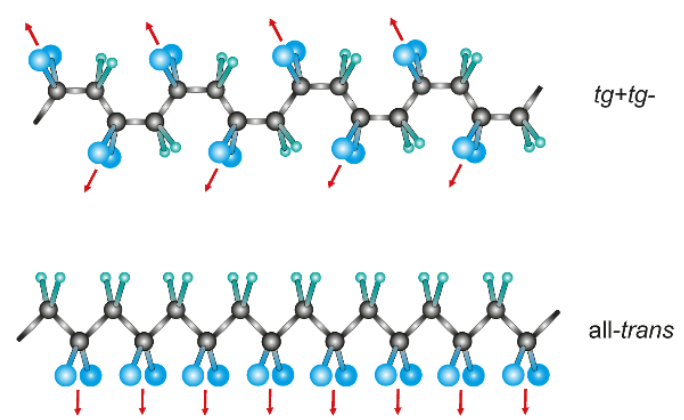
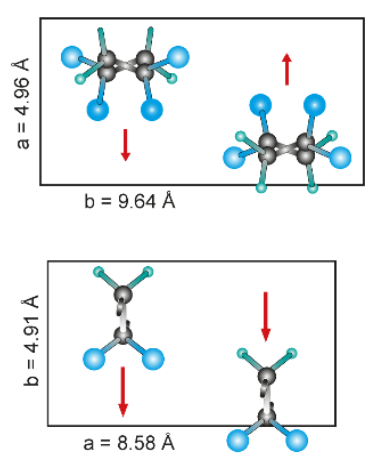

Figure 1. a) Crystalline lamellae and structural parameters of interest for dielectric properties. b) PVDF chain conformation and c) corresponding crystalline lattice parameters in the $\alpha$-phase $\left(\operatorname{tg}^{+} \operatorname{tg}^{-}\right)$(top panel) and $\beta$-phase (all-trans) (bottom panel).

Bulk films of $\mathrm{P}(\mathrm{VDF}-c o$-TrFE) $c o$-polymers with high VDF-content are highly crystalline and tend to crystallize with relatively thick crystalline lamellae $\left(L_{c} \sim 10 \mathrm{~nm}\right) .{ }^{9}$ The all-trans polymer chain conformation (Fig. 1b), which is the most stable in these lamellae, also ensures the formation of closely-packed crystalline lamellae, i.e. with high density (low inter-chain distance, Fig. 1c). The high crystallinity and low inter-chain distance induce a high maximum macroscopic polarization $\left(P_{\max }\right)$, but also leads to a high remanent polarization, responsible for a strong hysteresis, and high-temperature Curie temperature $\left(T_{C}\right)$; i.e. the temperature of the structural phase transition from the polar phase to the non-polar paraelectric (PE) phase, for which the ECE is maximized. Therefore, strategies were developed to shift $T_{C}$ closer to roomtemperature and decrease $P_{r}$ while maintaining a high $P_{\max }$. The introduction of a third larger co-monomer to form ter-polymer sequences such as $\mathrm{P}(\mathrm{VDF}-$ ter-TrFE-ter-CFE) and P(VDFter-TrFE-ter-CTFE) has looked especially promising. These ter-polymers have a comparatively higher inter-chain distance than $\mathrm{P}(\mathrm{VDF}-\mathrm{co}$-TrFE) due to the addition of bulky groups, such as chlorofluoroethylene (CFE), ${ }^{10}$ and crystallize in thinner lamellae due to the difficulty to include these bulky groups inside the crystal. The increase in inter-chain distance leads to a stabilization 
of the $\operatorname{tg}^{+} \operatorname{tg}^{-}$chain conformation and an expansion of the crystalline unit cell, which shifts $T_{C}$ to lower temperatures. Due to the higher distance between dipoles, $P_{r}$ is also decreased. The newly formed crystalline phase with a broad phase transition near room temperature, high $\varepsilon_{\max }$ and $P_{\text {max }}$ but low $P_{r}$, is referred to as relaxor ferroelectric (RFE). The combination of these properties has made P(VDF-ter-TrFE-ter-CFE) the standout candidate for ECE cooling, with encouraging values $\Delta T_{E C}>2 \mathrm{~K}$ reported at moderate electric fields $\left(\sim 50 \mathrm{MV} \cdot \mathrm{m}^{-1}\right) .^{8,11-16}$

Engineering the microstructure of the materials to further improve their ECE performance has been a key feature of recent polymer-based ECE research. Nano-composites with high permittivity nano-particles ${ }^{17}$ or nano-confinement in alumina templates ${ }^{8}$ have yielded interesting results. As an all-organic alternative, we have recently shown that a preferential extension of the crystalline lamellae in the plane including the polar direction could induce a significant dielectric and electrocaloric enhancement in double-bonds modified polymers, with an ECE enhancement $>60 \%$ measured near room-temperature. ${ }^{5}$ However, such a preferential crystalline growth is difficult to obtain without simultaneous lamellar thickening, which tends to concurrently decrease the permittivity.

Blending several VDF-based polymers has also been used to manipulate their microstructure. Chen et al. reported that blending $\mathrm{P}(\mathrm{VDF}-$ ter-TrFE-ter-CFE) (62.5/29/8.5) with $\mathrm{P}(\mathrm{VDF}-$-co-TrFE) (55/45) could induce a $30 \%$ increase in polarization, and the corresponding ECE, due to an interfacial coupling between the relaxor ter-polymer and normal ferroelectric co-polymer. ${ }^{18}$ While these results are promising, the beneficial approach of blending a relaxor with a ferroelectric co-polymer could push forward if the two polymers were allowed to cocrystallize. The addition of the co-polymer could then directly influence the density of the P(VDF-terTrFE-ter-CFE) crystalline lamellae and even induce a preferential growth in the polar direction, due to the maintained limitation of lamellar thickening provided by the presence of -CFE units. 
Here we blend P(VDF-ter-TrFE-ter-CFE) (63/30/7) with various amounts ( $1 \mathrm{wt} \%$ to $15 \mathrm{wt} \%)$ of $\mathrm{P}(\mathrm{VDF}-\mathrm{co}$-TrFE) (70/30). The strong FE behaviour of the co-polymer resulting from the high VDF-content ensures a drastic effect on the structural and dielectric properties of the terpolymer, thus limiting the required quantity of added co-polymer to only minute amounts $(<5$ wt $\%$ ). Furthermore, the similar VDF/TrFE unit ratio $(\sim 2)$ between both electroactive materials is shown to facilitate their cocrystallization.

The dielectric properties, as well as the direct ECE, were characterised in films prepared from the polymer blends. Fig. 2a shows that the permittivity is increased in the blends with low copolymer loading, without a significant shift of the temperature of maximum permittivity $\left(T_{\max }\right)$. The maximum permittivity at $1 \mathrm{kHz}$, increases from 48 for the neat terpolymer to 51 for the 1 $\mathrm{wt} \%$ blend. However, for high co-polymer contents (10 and $15 \mathrm{wt} \%)$, the blending strategy is detrimental as a shift of $T_{\max }$ from $29{ }^{\circ} \mathrm{C}$ to $45^{\circ} \mathrm{C}$, associated with a reduction in permittivity, is observed. Similar differences are observed in the polarization versus electric field at RT; for low co-polymer contents, especially $1 \mathrm{wt} \%$ and $2 \mathrm{wt} \%$, the maximum polarization $P_{\max }$ is significantly increased in the blends, from $5.4 \mu \mathrm{C} \cdot \mathrm{cm}^{-2}$ to $6.2 \mu \mathrm{C} \cdot \mathrm{cm}^{-2}$ at $170 \mathrm{MV} \cdot \mathrm{m}^{-1}$, while the remanent polarization $P_{r}$ remains relatively unchanged. As previously mentioned, this trend is highly desirable for ECE enhancement, as it ensures high polarization while maintaining the reversibility of the ECE, which allows for an efficient ECE cooling cycle to be established. However, when the co-polymer loading is increased further, an increase of the remanent polarization is concurrently observed (Fig. 2b), from $P_{r}=0.3 \mu \mathrm{C} \cdot \mathrm{cm}^{-2}$ measured on the neat ter-polymer to $P_{r}=2.6 \mu \mathrm{C} \cdot \mathrm{cm}^{-2}$ for the $15 \mathrm{wt} \%$ blend. This trend is in good agreement with the shift of $T_{\max }$ toward high temperature observed in Fig. 2 a. 

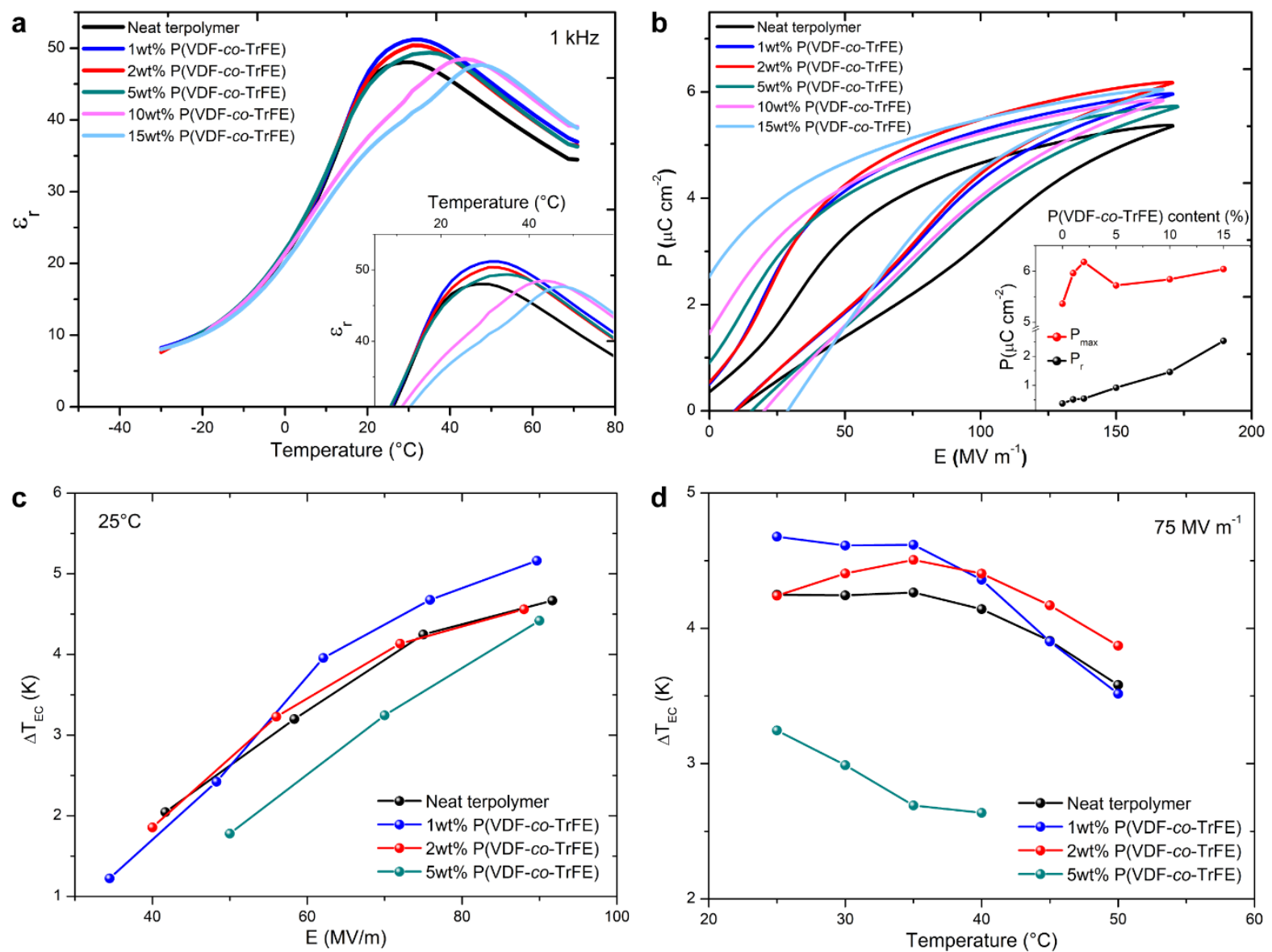

Figure 2. Comparison of the dielectric and electrocaloric properties measured on the neat $\mathrm{P}(\mathrm{VDF}-$ ter-TrFE-ter-CFE) ter-polymer and blends with various contents of $\mathrm{P}(\mathrm{VDF}-$-co-TrFE $)$ : a) Real part of the permittivity $v s$. temperature at $1 \mathrm{kHz}, \mathbf{b})$ polarization $v s$. electric field $(P-E$ loop) measured at $100 \mathrm{~Hz}$, with a maximum field of $170 \mathrm{MV} \cdot \mathrm{m}^{-1}$, c) direct electrocaloric adiabatic temperature change $v s$. electric field at RT, and d) direct electrocaloric adiabatic temperature change $v s$. temperature at $75 \mathrm{MV} \cdot \mathrm{m}^{-1}$. The inset of b) shows the evolution of the maximum and remanent polarization measured at $170 \mathrm{MV} \cdot \mathrm{m}^{-1}$ and $\mathrm{RT}$.

Direct measurements of the adiabatic temperature change, $\Delta T_{E C}$, on the blends with low copolymer loading revealed an electrocaloric enhancement in the $1 \mathrm{wt} \% \mathrm{P}(\mathrm{VDF}-\mathrm{co}-\mathrm{TrFE})$ blend for moderate electric fields at RT. A maximum $\Delta T_{E C}=5.2 \mathrm{~K}$ was measured for this particular blend under a $90 \mathrm{MV} \cdot \mathrm{m}^{-1}$ electric field, while the neat terpolymer registered $\Delta T_{E C}=4.6 \mathrm{~K}$ in 
the same conditions (Fig. 2c). For a more moderate electric field of $62 \mathrm{MV} \cdot \mathrm{m}^{-1}, \Delta T_{E C}=4.0 \mathrm{~K}$ was measured on the same blend, which rivals with the best EC performance reported to date by direct measurements for $\mathrm{E} \leq 60 \mathrm{MV} \cdot \mathrm{m}^{-1}$ on polymers and nano-composites, $\Delta T_{E C} \sim 3.5-4.2$ $\mathrm{K},{ }^{14,18-21}$ (see Table S1, supporting information) but remains lower than the best ceramic multilayer capacitors $\left(\Delta T_{E C} \sim 5.5 \mathrm{~K}\right){ }^{22}$ The ECE measured in the $2 \mathrm{wt} \%$ blend is similar to the results for the neat ter-polymer, while the room temperature ECE clearly starts to decrease when the co-polymer content is increased to $5 \mathrm{wt} \%$. A study of the ECE versus temperature at a given electric field revealed that the ECE enhancement is observed at higher temperature in the $2 \mathrm{wt} \%$ blend, when compared to the $1 \mathrm{wt} \%$ blend, most probably due to the slight shift in the phase transition temperature. For temperature above $40{ }^{\circ} \mathrm{C}$, the highest ECE is measured in the $2 \mathrm{wt} \%$ blend (Fig. 2d). All the data of the electrocaloric isothermal heat change and $\Delta T_{E C}$ versus $E$ and $T$ obtained by direct measurements on the neat ter-polymer and blends is supplied in supporting information (Fig. S1). 

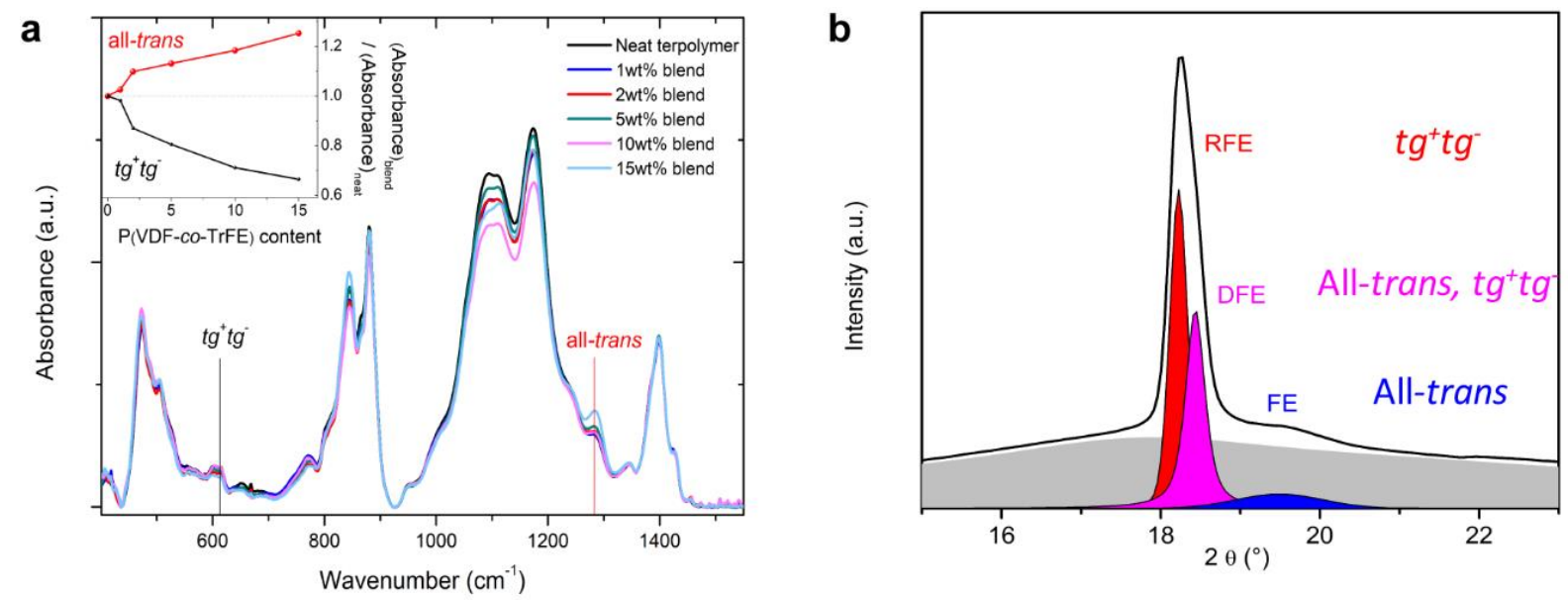

C
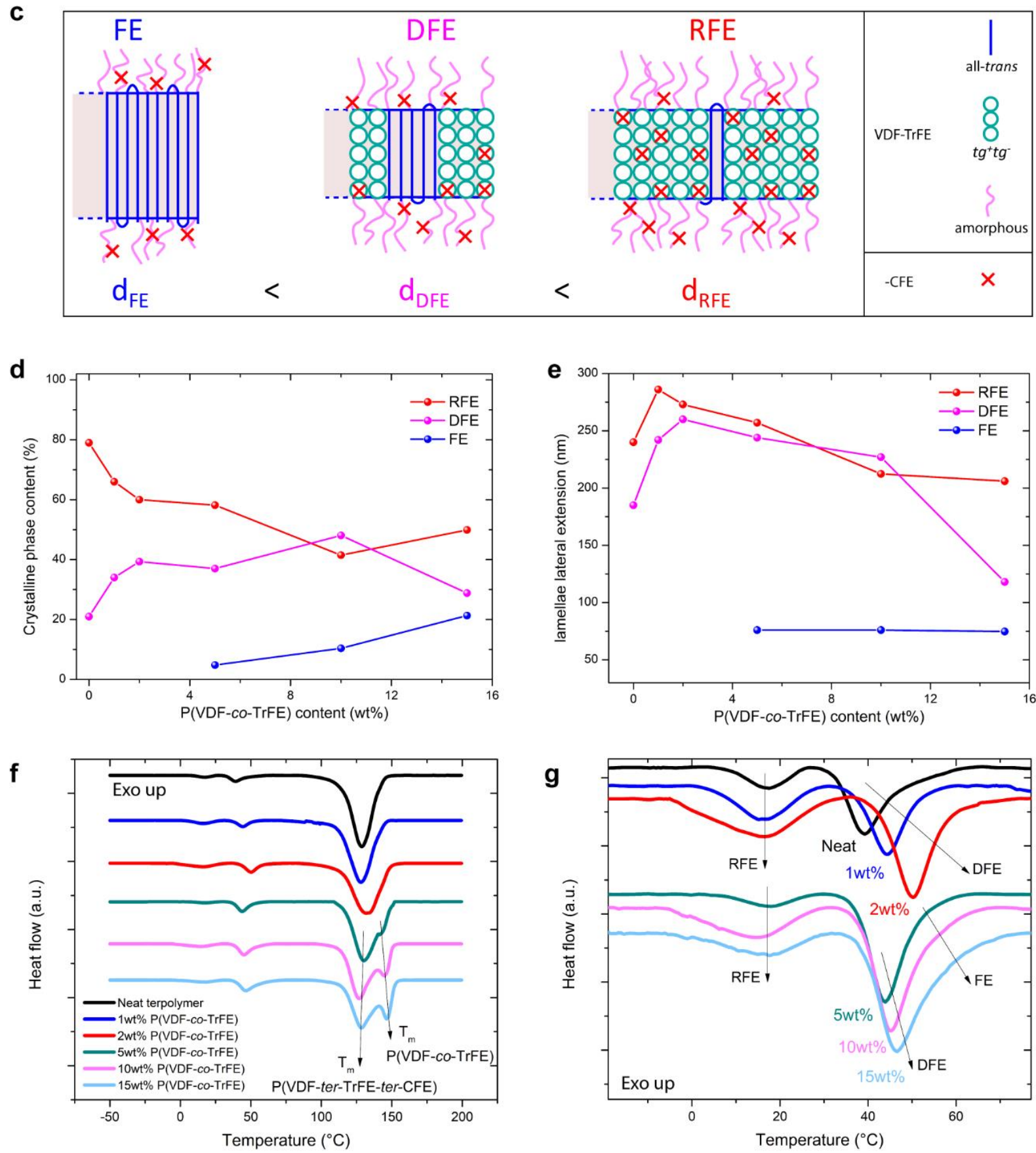
Figure 3. Evolution of the structural parameters of the neat P(VDF-ter-TrFE-ter-CFE) terpolymer and blends with various contents of $\mathrm{P}(\mathrm{VDF}-\mathrm{co}$-TrFE): a) FT-IR spectroscopy. The inset shows ratio of the relative absorbance of the blends with that of the neat ter-polymer for a specific $\operatorname{tg}^{+} t g^{-}$vibration $\left(610 \mathrm{~cm}^{-1}\right)$ and a specific all-trans vibration $\left(1283 \mathrm{~cm}^{-1}\right)$ for each blend compared with the same ratio obtained for the neat ter-polymer. b) Deconvolution of a typical WAXS spectrum associated with the juxtaposition of the two diffraction lines resulting from the (200) and (110) planes, and corresponding crystalline phases, namely RFE, DFE and FE. c) Schematic representation of the crystalline lamellae of each of the three crystalline phases with relative comparison of their inter-planar distance. d) Crystalline phase content and e) lateral extension of the crystalline lamellae versus co-polymer content. f) full temperaturerange and g) low-temperature range of the differential scanning calorimetry thermograms (first heating, $\left.10{ }^{\circ} \mathrm{C} \cdot \mathrm{min}^{-1}\right)$.

A wide range of structural characterisation was performed on these polymer films to identify the origin of the changes measured in the dielectric and electrocaloric properties. A gradual increase of the all-trans conformation with increasing co-polymer content was observed with Fourier-transform infra-red spectroscopy (FT-IR). For each co-polymer loading, the ratio of the relative absorbance of the blends with that of the neat ter-polymer were monitored for a specific $\operatorname{tg}^{+} \operatorname{tg}^{-}$vibration $\left(610 \mathrm{~cm}^{-1}\right)$ and a specific all-trans specific vibration $\left(1283 \mathrm{~cm}^{-1}\right)$ as shown in the inset of Fig. 3a. The result of this comparison clearly demonstrates the increase of the alltrans conformation over the $\operatorname{tg}^{+} \mathrm{tg}^{-}$conformation. This evolution is a direct consequence of the increase of the co-polymer content, which favours the all-trans conformation for these VDFcontents. 
The effect of blending on the crystalline lamellae of P(VDF-ter-TrFE-ter-CFE) was then studied by Wide-Angle X-Ray Scattering (WAXS). The typical WAXS spectrum associated with the juxtaposition of the two diffraction lines resulting from the (200) and (110) planes in the $\mathrm{P}(\mathrm{VDF}-$ ter-TrFE-ter-CFE) / P(VDF-co-TrFE) blends is shown in Fig. 3b (All WAXS spectra are provided in Supporting Information, see Fig. S2 and S3). Up to three different crystalline phases can be identified depending on the stable chain conformations inside the crystalline lamellae, which affects the inter-planar distance and consequently, the diffraction angle $2 \theta^{5,23,24}$ The relaxor ferroelectric phase (RFE) comprises mostly gauche defects, it displays a higher inter-planar distance and a lower $2 \theta$. On the other hand, the all-trans chain conformation is inherent to the ferroelectric (FE) crystals, thus leading to a denser crystalline phase (low inter-planar distance) and higher $2 \theta$. Finally, a third phase has been identified, with an intermediate amount of gauche defects, mostly concentrated near the interface of the crystalline lamellae, as shown in Fig. 3 c. $^{23,24}$ This phase is referred to as defective ferroelectric (DFE); the diffraction angle of its (200)/(110) Bragg peak is found between that of the RFE and the FE phases. Consistently with FT-IR, WAXS revealed that the blending with the ferroelectric co-polymer led to a gradual increase of the all-trans containing crystalline phase contents, namely DFE and FE, as shown in Fig. 3d. For low co-polymer contents, only the DFE phase is stabilised, while the FE phase is also present for higher co-polymer loading, especially $10 \mathrm{wt} \%$ and $15 \mathrm{wt} \%$. Even if the existence of P(VDF-ter-TrFE-ter-CFE) FE crystalline lamellae cannot be discarded, the majority of the FE lamellae is associated with P(VDF-co-TrFE) crystals. The presence of this denser phase explains the differences observed in the dielectric properties, with a shift of the phase transition to higher temperature and a $P_{r}$ increase.

Interestingly, WAXS also revealed an extension of the lateral coherence of both the RFE and DFE lamellae for low co-polymer contents $(\leq 2 \mathrm{wt} \%)$, while a reduction was noticed for the blends with high loading. The lateral extension ( $\xi_{200 / 110}$, schematically represented on Fig. 1a) 
was obtained by applying the Scherrer formula to the width-at-half-maximum, $\Delta 2 \theta_{200 / 110}$, of the Bragg peak for each crystalline phase. ${ }^{25}$ For the blends with $1 \mathrm{wt} \%$ and $2 \mathrm{wt} \%$ of co-polymer, where the significant dielectric and electrocaloric enhancement was observed, the lateral coherence of both the RFE and DFE lamellae is extended, with a large $\xi_{200 / 110} \sim 300 \mathrm{~nm}$ estimated for the $1 \mathrm{wt} \%$ blend (Fig. 3e). However, crystalline lamellae with similar lateral extension as that of the neat ter-polymer were obtained when the co-polymer content is increased to $5 \mathrm{wt} \%$. The lateral extension of the RFE and DFE lamellae then decreases further for higher co-polymer loading. In the meantime, the lateral extension of the FE crystalline lamellae remains relatively unchanged. These results further confirm the direct correlation between preferential lateral extension of the crystalline lamellae and dielectric and electrocaloric enhancement in VDF-based ter-polymers. ${ }^{5}$

Differential scanning calorimetry (DSC) was also used to monitor the evolution of the crystalline lamellar thickness from the position of the melting endotherm upon heating. DSC revealed that the lamellar thickness of the main crystalline phase remained relatively unaffected by the blending, as indicated by the position of the melting peak, which remained near $130{ }^{\circ} \mathrm{C}$ $\left(10^{\circ} \mathrm{C} / \mathrm{min}\right.$, Fig. $\left.3 \mathrm{f}\right)$. However, the emergence of a second melting endotherm can be observed at higher temperature for co-polymer contents $\geq 5 \mathrm{wt} \%$, which corresponds to another population of crystalline lamellae with larger lamellar thickness. The shift toward higher temperature of this second melting endotherm further accentuates with increasing co-polymer content. 


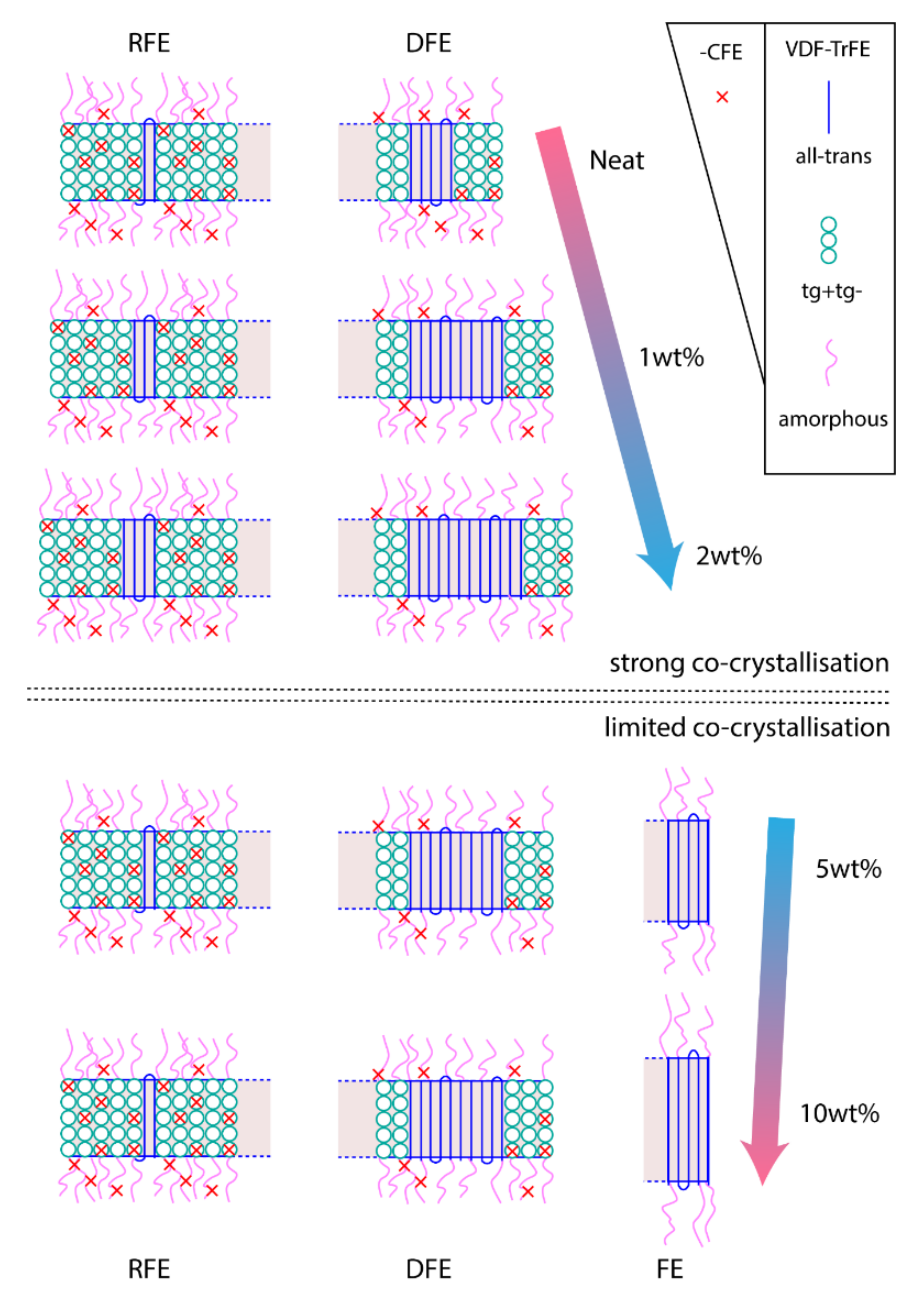

Figure 4. Schematic representation of the evolution of the crystalline lamellae of each of the three crystalline phases (RFE, DFE and FE) when increasing the co-polymer content in the $\mathrm{P}(\mathrm{VDF}-$ ter-TrFE-ter-CFE)/P(VDF-co-TrFE) blends. A special emphasis was placed on monitoring the evolution of the crystalline lamellae thickness and lateral extension, as well as their content in $\operatorname{tg}^{+} \mathrm{tg}^{-}$and all-trans polymer chain conformation.

A closer look at the low-temperature end of the DSC thermograms sheds further light on how the addition of small contents of $\mathrm{P}(\mathrm{VDF}-\mathrm{co}$-TrFE) $c o$-polymer induces a lateral extension of the RFE and DFE crystalline lamellae of P(VDF-ter-TrFE-ter-CFE). Two endotherms can clearly be identified for the neat ter-polymer (Fig. 3g), one at $\sim 20^{\circ} \mathrm{C}$ and one at $\sim 40{ }^{\circ} \mathrm{C}$, which 
correspond to the RFE to PE ( $\left.T_{\mathrm{RFE}-\mathrm{PE}}\right)$ and the DFE to PE ( $\left.T_{\mathrm{DFE}-\mathrm{PE}}\right)$ phase transitions, respectively. $T_{\mathrm{DFE}-\mathrm{PE}}$ clearly shifts to high temperature in the $1 \mathrm{wt} \%$ and $2 \mathrm{wt} \%$ blends, as a result of the DFE phase densification, confirmed by the decrease of the inter-planar distance (see Fig. S4). This result, combined with the lateral crystalline coherence extension of the lamellae measured for these co-polymer contents, indicates that the two VDF-polymers cocrystallize. Fig. 4 shows a schematic representation of the evolution of the crystalline lamellae of each phase with increasing co-polymer content as deduced from our dielectric and structural characterisations. For $1 \mathrm{wt} \%$ and $2 \mathrm{wt} \%$, the similar VDF/TrFE ratios ( 2) in both polymers allows for a cocrystallization of the co-polymer VDF-TrFE chains in the P(VDF-terTrFE-ter-CFE) lamellae. These results in a "growth" of both the RFE and DFE crystalline lamellae, but, as the lamellar thickening is still strongly hampered by the presence of CFE groups at the crystalline/amorphous interface, this crystalline "growth" is mainly restricted to the lateral plane, and the lamellar thickness remains unchanged, as confirmed by the constant melting temperature observed in DSC. This cocrystallization results in a densification of the lamellae and an increase of their content in polymer chains with all-trans conformation. The cocrystallization is more important in the DFE phase than in RFE phase, as a result of the already lower inter-planar distance of the DFE phase. This lateral extension without lamellar thickening, along with the slight densification of the lamellae, is responsible for the observed increase of the maximum permittivity and polarization $\left(P_{\max }\right)$, without a detrimental increase in remanent polarization $\left(P_{r}\right)$. Furthermore, $\Delta T_{E C}$ for a given temperature $T$ is defined as

$$
\Delta T_{E C}=\frac{\beta T}{2 \rho C_{p}}\left(P_{\max }^{2}-P_{r}^{2}\right)
$$

Where $\rho$ is the density, $C_{p}$ the specific heat capacity and $\beta$ a materials' specific constant ${ }^{2}$.

Consequently, as $\Delta T_{E C}$ is proportional to the electric-field induced polarization change, $P_{\max }^{2}-$ $P_{r}^{2}$, this cocrystallization also leads to an enhancement of $\Delta T_{E C}$ in the temperature range where 
the largest change in polarization can be found, i.e. in the vicinity of $T_{\mathrm{RFE}-\mathrm{PE}}$ and $T_{\mathrm{DFE}-\mathrm{PE}}$. Therefore, an EC enhancement is observed between $25^{\circ} \mathrm{C}$ and $40{ }^{\circ} \mathrm{C}$ for the $1 \mathrm{wt} \%$ blend, while this temperature range is shifted to $30{ }^{\circ} \mathrm{C}-50{ }^{\circ} \mathrm{C}$ in the $2 \mathrm{wt} \%$ blend (Fig. $2 \mathrm{~d}$ and Fig S1), in accordance with the shift of $T_{\mathrm{DFE}-\mathrm{PE}}$ to higher temperature.

However, when the co-polymer content is increased further ( $\geq 5 \mathrm{wt} \%)$, the co-polymer VDFTrFE chains start to independently crystallize as well. As they do not contain any -CFE groups, they can form thicker crystalline lamellae (Fig. 4), which explains the emergence of the second melting endotherm at higher temperature observed in DSC. The lamellar thickening then increases further for high co-polymer contents. The $\mathrm{P}(\mathrm{VDF}-\mathrm{co}-\mathrm{TrFE})$ lamellae contain a majority of chains in the all-trans conformation, resulting in the presence of the much denser FE crystalline phase observed in WAXS for contents $\geq 5 \mathrm{wt} \%$. Furthermore, their crystallization is easier than for $\mathrm{P}(\mathrm{VDF}-$ ter-TrFE-ter-CFE) due to their higher chain mobility, concurrently hindering the crystallization of the other phases while decreasing the propensity of cocrystallization, as evidenced by the shift back to lower temperature of $T_{\mathrm{DFE}-\mathrm{PE}}$ in the DSC from $2 \mathrm{wt} \%$ to $5 \mathrm{wt} \%$, the increase of the inter-chain distance of DFE and RFE lamellae, and the decrease of the lateral extension for contents $\geq 5 \mathrm{wt} \%$.

In summary, blending relaxor ferroelectric $\mathrm{P}(\mathrm{VDF}-$ ter-TrFE-ter-CFE) ter-polymer with low amounts $(\leq 2 \mathrm{wt} \%)$ of high-VDF-content ferroelectric $\mathrm{P}(\mathrm{VDF}-\mathrm{co}-\mathrm{TrFE})$ co-polymer led to an enhancement of the dielectric and electrocaloric properties near room temperature. A remarkable polarization $P_{\max }=6.2 \mu \mathrm{C} \cdot \mathrm{cm}^{-2}\left(100 \mathrm{~Hz}, 170 \mathrm{MV} \cdot \mathrm{m}^{-1}\right)$ and electrocaloric effect $\Delta T_{E C}=5.2 \mathrm{~K}$ for a moderate electric field of $90 \mathrm{MV} \cdot \mathrm{m}^{-1}$ was measured in the blend with $1 \mathrm{wt} \%$ of co-polymer. Increasing the co-polymer content further ( $\geq 5 \mathrm{wt} \%)$ was found to be detrimental to the electrocaloric performance, due to a shift of the phase transition temperature to higher temperature and an increase of the remanent polarization. A suite of structural characterisation 
revealed the electrocaloric enhancement to be the result of a cocrystallization of the P(VDF-coTrFE) chains in the $\mathrm{P}(\mathrm{VDF}-$ ter-TrFE-ter-CFE) crystalline lamellae, facilitated by the similar $\mathrm{VDF} / \mathrm{TrFE}$ ratio. This cocrystallization induced an extension of the lateral coherence of the crystalline lamellae, without lamellar thickening, as well as a slight decrease of the inter-planar distance. However, when the co-polymer content was increased further, $\mathrm{P}(\mathrm{VDF}-\mathrm{co}$-TrFE) was found to crystallize independently into much denser and thicker crystalline lamellae, hindering the cocrystallization and the crystallization of $\mathrm{P}(\mathrm{VDF}-\mathrm{ter}$-TrFE-ter-CFE), which proved detrimental to the dielectric and electrocaloric properties near room temperature.

These results highlight the importance of elucidating structure/property relationships in VDFbased polymers and open the door to a new method for electrocaloric enhancement, through the cocrystallization induced directed growth of the crystalline lamellae in the plane where the polar direction lies.

\section{Supporting Information}

Supporting Information is available free of charge via the Internet at http://pubs.acs.org. All experimental details are included, with the description of the materials used, the methods for film and device fabrication, as well as detailed procedures and lists of the instruments and characterization techniques used to obtain the results presented here. Also included are the isothermal heat change and adiabatic temperature change data obtained by direct measurement as a function of electric field and temperature (Fig. S1), as well the WAXS spectra (Fig. S2), their deconvolution (Fig. S3) and the corresponding inter-planar distance $\mathrm{d}_{200} / \mathrm{d}_{110}$ (Fig. S4), for the neat ter-polymer and all the blend compositions. Finally, a table listing the best reported adiabatic temperature changes measured on polymers, nano-composites and ceramics for $\mathrm{E} \leq$ $60 \mathrm{MV} \cdot \mathrm{m}^{-1}$ is provided (Table $\left.\mathrm{S} 1\right)$. 


\section{Acknowledgements}

The authors acknowledge the financial support from the Industrial Chair SMILE within the grant agreement no. ANR-19-CHIN-0002. N. P. acknowledges the IDEx Associated International Chair entitled MARBLE. This work was performed within the framework of the Equipex ELORPrintTec ANR-10-EQPX-28-01 with the help of the French state's Initiative d'Excellence IdEx ANR-10-IDEX-003-02. The authors also thank Arkema-Piezotech (France) for providing the materials used in the study.

\section{Conflict of interest}

The authors declare no conflict of interest.

\section{References}

(1) Correia, T.; Zhang, Q. Electrocaloric Materials; Correia, T., Zhang, Q., Eds.; Engineering Materials; Springer: Berlin, Heidelberg, 2014.

(2) Webster, J. G.; Kutnjak, Z.; Rožič, B.; Pirc, R. Electrocaloric Effect: Theory, Measurements, and Applications. In Wiley Encyclopedia of Electrical and Electronics Engineering; John Wiley \& Sons, Inc., 2015; pp 1-19.

(3) Le Goupil, F.; Berenov, A.; Axelsson, A.-K.; Valant, M.; Alford, N. M. Direct and Indirect Electrocaloric Measurements on $\langle 001\rangle-\mathrm{Pb}(\mathrm{Mg} 1 / 3 \mathrm{Nb} 2 / 3) \mathrm{O} 3-30 \mathrm{PbTiO} 3$ Single Crystals. J. Appl. Phys. 2012, 111 (12), 124109.

(4) Shi, J.; Han, D.; Li, Z.; Yang, L.; Lu, S.-G.; Zhong, Z.; Chen, J.; Zhang, Q. M.; Qian, 
X. Electrocaloric Cooling Materials and Devices for Zero-Global-Warming-Potential, High-Efficiency Refrigeration. Joule 2019, 3 (5), 1200-1225.

(5) Le Goupil, F.; Kallitsis, K.; Tencé-Girault, S.; Pouriamanesh, N.; Brochon, C.; Cloutet, E.; Soulestin, T.; Domingue Dos Santos, F.; Stingelin, N.; Hadziioannou, G. Enhanced Electrocaloric Response of Vinylidene Fluoride-Based Polymers via One-Step Molecular Engineering. Adv. Funct. Mater. 2021, 31 (1), 2007043.

(6) Neese, B.; Chu, B.; Lu, S.-G.; Wang, Y.; Furman, E.; Zhang, Q. M. Large Electrocaloric Effect in Ferroelectric Polymers Near Room Temperature. Science (80-. ). 2008,321 (5890), 821-823.

(7) Ma, R.; Zhang, Z.; Tong, K.; Huber, D.; Kornbluh, R.; Ju, Y. S.; Pei, Q. Highly Efficient Electrocaloric Cooling with Electrostatic Actuation. Science 2017, 357 (6356), 1130-1134.

(8) Zhang, G.; Weng, L.; Hu, Z.; Liu, Y.; Bao, R.; Zhao, P.; Feng, H.; Yang, N.; Li, M.-Y.; Zhang, S.; Jiang, S.; Wang, Q. Nanoconfinement-Induced Giant Electrocaloric Effect in Ferroelectric Polymer Nanowire Array Integrated with Aluminum Oxide Membrane to Exhibit Record Cooling Power Density. Adv. Mater. 2019, 1806642.

(9) Bargain, F.; Soulestin, T.; Santos, F. D. dos; Ladmiral, V.; Tencé-Girault, S.; Ameduri, B. Semicrystalline Organization of VDF- and TrFE-Based ElectroactiveTerpolymers: Impact of the Trans-1,3,3,3-TetrafluoropropeneTermonomer. Macromolecules 2017, $50(8), 3313-3322$.

(10) Yang, L.; Li, X.; Allahyarov, E.; Taylor, P. L.; Zhang, Q. M.; Zhu, L. Novel Polymer Ferroelectric Behavior via Crystal Isomorphism and the Nanoconfinement Effect. Polymer 2013, 54 (7), 1709-1728. 
(11) Liu, P. F.; Wang, J. L.; Meng, X. J.; Yang, J.; Dkhil, B.; Chu, J. H. Huge Electrocaloric Effect in Langmuir-Blodgett Ferroelectric Polymer Thin Films. New J. Phys. 2010, 12 (2), 23035.

(12) Lu, B.; Chen, X.; Zhang, T.; Lu, S. G.; Zhang, Q. M. Enhancing the Electrocaloric Effect in a Relaxor Polymer by Including Minor Normal Ferroelectric Phase. Appl. Phys. Lett. 2018, 113 (15), 153903.

(13) Neese, B.; Lu, S. G.; Chu, B.; Zhang, Q. M. Electrocaloric Effect of the Relaxor Ferroelectric Poly(vinylidene Fluoride-Trifluoroethylene-Chlorofluoroethylene) Terpolymer. Appl. Phys. Lett. 2009, 94 (4), 42910.

(14) Li, X.; Qian, X.; Lu, S. G.; Cheng, J.; Fang, Z.; Zhang, Q. M. Tunable Temperature Dependence of Electrocaloric Effect in Ferroelectric Relaxor Poly(vinylidene FluorideTrifluoroethylene-Chlorofluoroethylene Terpolymer. Appl. Phys. Lett. 2011, 99 (5), 52907.

(15) Guo, D.; Gao, J.; Yu, Y.-J.; Santhanam, S.; Fedder, G. K.; McGaughey, A. J. H.; Yao, S. C. Electrocaloric Characterization of a Poly(vinylidene Fluoride-TrifluoroethyleneChlorofluoroethylene) Terpolymer by Infrared Imaging. Appl. Phys. Lett. 2014, 105 (3), 31906.

(16) Chen, X.; Qian, X.; Li, X.; Lu, S. G.; Gu, H.; Lin, M.; Shen, Q.; Zhang, Q. M. Enhanced Electrocaloric Effect in Poly(vinylidene Fluoride-Trifluoroethylene)-Based Terpolymer/copolymer Blends. Appl. Phys. Lett. 2012, 100 (22), 222902.

(17) Li, Q.; Zhang, G.; Zhang, X.; Jiang, S.; Zeng, Y.; Wang, Q. Relaxor FerroelectricBased Electrocaloric Polymer Nanocomposites with a Broad Operating Temperature Range and High Cooling Energy. Adv. Mater. 2015, 27 (13), 2236-2241. 
(18) Chen, X.-Z.; Li, X.; Qian, X.-S.; Wu, S.; Lu, S.-G.; Gu, H.-M.; Lin, M.; Shen, Q.-D.; Zhang, Q. M. A Polymer Blend Approach to Tailor the Ferroelectric Responses in P(VDF-TrFE) Based Copolymers. Polymer 2013, 54 (9), 2373-2381.

(19) Qian, J.; Guo, M.; Jiang, J.; Dan, Z.; Shen, Y. Enhanced Electrocaloric Strength of P(VDF-TrFE-CFE) Induced by Edge-on Lamellae. J. Mater. Chem. C 2019, 7 (11), $3212-3217$.

(20) Chen, X.; Xu, W.; Lu, B.; Zhang, T.; Wang, Q.; Zhang, Q. M. Towards Electrocaloric Heat pump-A Relaxor Ferroelectric Polymer Exhibiting Large Electrocaloric Response at Low Electric Field. Appl. Phys. Lett. 2018, 113 (11), 113902.

(21) Zhang, G.; Li, Q.; Gu, H.; Jiang, S.; Han, K.; Gadinski, M. R.; Haque, M. A.; Zhang, Q.; Wang, Q. Ferroelectric Polymer Nanocomposites for Room-Temperature Electrocaloric Refrigeration. Adv. Mater. 2015, 27 (8), 1450-1454.

(22) Nair, B.; Usui, T.; Crossley, S.; Kurdi, S.; Guzmán-Verri, G. G.; Moya, X.; Hirose, S.; Mathur, N. D. Large Electrocaloric Effects in Oxide Multilayer Capacitors over a Wide Temperature Range. Nature 2019, 575 (7783), 468-472.

(23) Bargain, F.; Panine, P.; Domingues Dos Santos, F.; Tencé-Girault, S. From SolventCast to Annealed and Poled poly(VDF-Co-TrFE) Films: New Insights on the Defective Ferroelectric Phase. Polymer 2016, 105, 144-156.

(24) Bargain, F.; Thuau, D.; Panine, P.; Hadziioannou, G.; Domingues Dos Santos, F.; Tencé-Girault, S. Thermal Behavior of poly(VDF-Ter-TrFE-Ter-CTFE) Copolymers: Influence of CTFE Termonomer on the Crystal-Crystal Transitions. Polymer 2019, $161,64-77$.

(25) Klug, H.; Alexander, L. X-Ray Diffraction Procedures: For Polycrystalline and 
Amorphous Materials, 2nd Edition. Willey, New York, EUA. 1974, p 992. 


\section{Table of Contents}

Electrocaloric Enhancement Induced by Cocrystallization of Vinylidene Difluoride-Based Polymer Blends.

Florian Le Goupil*, Francesco Coin, Naser Pouriamanesh, Guillaume Fleury, and Georges Hadziioannou*.

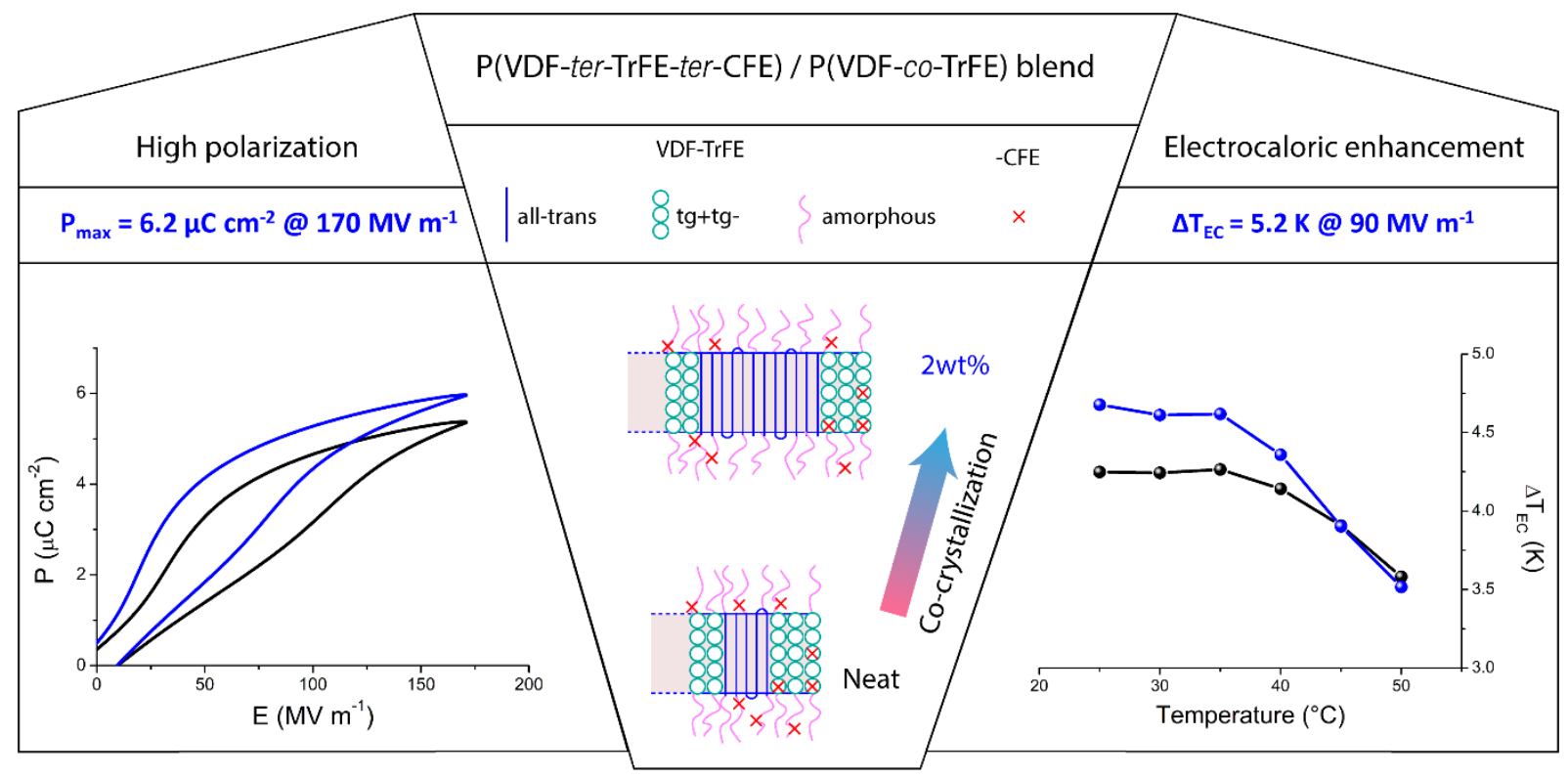

for Table of Contents use only 